\title{
Biological wastewater treatment using regenerated immobilized sludge
}

\author{
Victor N. Kulkov ${ }^{1, *}$ \\ ${ }^{1}$ Irkutsk National Research Technical University, Department of Engineering Communications and \\ Life Support Systems, 83 Lermontov St., Irkutsk, 664074, Russian Federation
}

\begin{abstract}
The purpose of this work is to study biological wastewater treatment using air regeneration of immobilized sludge in an aerotank-bioreactor. For the experiment, physical modeling of gashydrodynamic processes in aerated wastewater treatment plants was used. An experimental laboratory setup for studying the distribution of activated sludge and the oxidizing capacity of a bioreactor has been developed and installed. Methods for investigating water-air regeneration of synthetic inert loading in a physical model of a bioreactor are described. To determine the concentration of free-floating sludge in the bioreactor, a calibration graph method was used, i.e. the dependence of the concentration of free-floating sludge on the intensity of light passing through the water-sludge mixture was constructed. The kinetics of biological treatment was studied by BOD and oxygen dissolved in wastewater in the presence of two biocenoses of sludge adsorbed on an inert ruff load and floating in a bioreactor. The method of processing the experimental data obtained using luxmeters using a calibration graph allows one to obtain the values of the concentration of freefloating and immobilized sludge in dynamics. It is shown that the periodic regeneration (renewal) of the immobilized sludge makes it possible to increase the rate and depth of wastewater treatment.
\end{abstract}

\section{Introduction}

Increasing the dose of activated sludge in aerotanks using sludge immobilized on carriers is a modern and promising method for biological wastewater treatment. The use of regenerated immobilized sludge allows increasing the depth of biological wastewater treatment.

Microorganisms adsorbed on an inert load are not exposed to the negative impact of salvo concentrations of toxic substances, their uncontrolled removal from secondary sedimentation tanks, filamentous swelling, and so on, that is, to the impact of negative technological parameters of wastewater treatment. The immobilized biocenosis makes it possible to evenly distribute activated sludge throughout the entire volume of the bioreactor, maintaining its increased and fixed mass. Synthetic carriers of immobilized biocenosis need their periodic renewal from various large impurities and jelly-like mass with immobilized microorganisms [1-4].

The carriers of the immobilized biocenosis can be free floating loading and loading fixed in the biological treatment unit, made of varied materials and having different shapes, capable of increasing the sludge dose in the bioreactor to $8-10 \mathrm{~g} / \mathrm{dm}^{3}$ with reliable operation of secondary sedimentation tanks. [1, 2, 5-10]. A common material for an inert carrier of attached microflora is a brush loading made of nylon fiber, on which sedimentation occurs and uniform distribution of a significant specific mass of microorganisms $[4,11,12]$.

Corresponding author: kulkof.viktor@yandex.ru 
It is not possible to study the hydrodynamic conditions in aerated facilities of biological wastewater treatment under the conditions of existing treatment facilities. The study of the hydrodynamic situation in various technological modes of operation of a model aerotankbioreactor and the dissemination of the results to an industrial aerotank is possible using the theory of mechanical similarity of the movement of a real liquid [13-15], i.e. the need to meet the conditions of geometric, kinematic and dynamic similarity.

\section{Experimental part}

\subsection{Object and purpose of the study}

For research, in order to study the technology of using and regenerating immobilized sludge for wastewater treatment, a physical model of an aerotank-displacer is proposed, which is a vertical cross section of one corridor of a volumetric aerotank, i.e. model aerotankbioreactor (Figure 1).

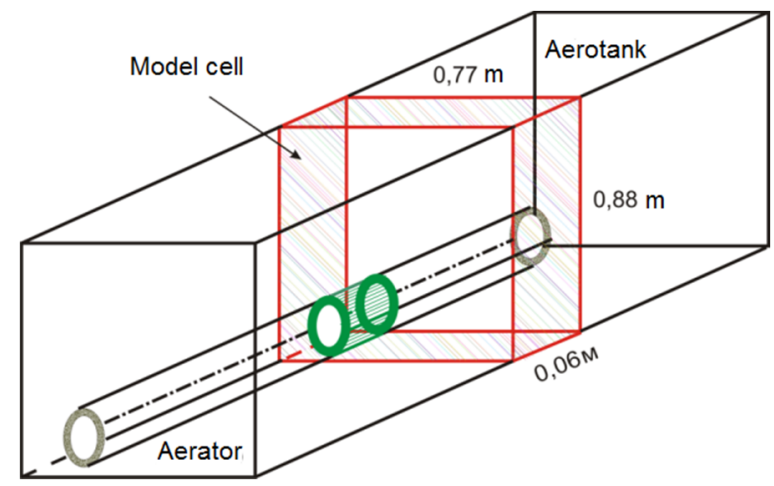

Fig. 1. Bioreactor model representing a vertical cross-section of one corridor of a volumetric aerotank

The study of the sedimentation of sludge on an inert synthetic load of the "brush" type and its regeneration was carried out on the physical model of the aerotank-bioreactor shown in Figure 2.

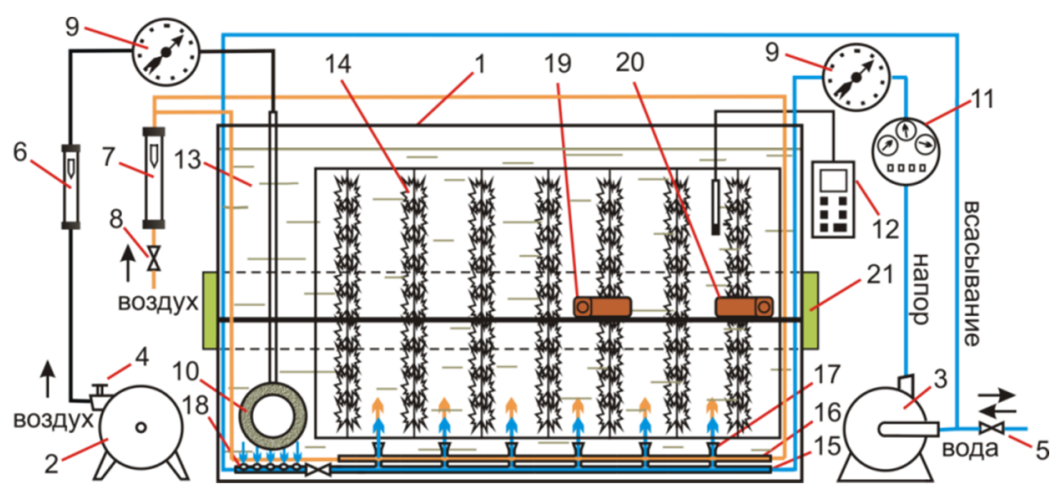

Fig. 2. Installation diagram and model of aerotank-bioreactor: 1 - model aerotank-bioreactor; 2 compressor with a receiver for aeration of water-sludge mixture; 3 - pumping unit for regeneration of an inert synthetic loading of the "brush" type; 4 - air flow control valve; 5 - fittings for filling and emptying the aerotank-bioreactor; 6 - rotameter RM- $0.63 \mathrm{GUZ}$ for measuring air consumption for aeration of water-sludge mixture; 7 - rotameter RM-6,3 GUZ for measuring air consumption for regeneration of inert synthetic loading of the "ruff" type; 8 - valve for regulating the air flow rate for the regeneration of the brush loading; 9 - manometers; 10 - fine-bubble aerator; 11 - water meter; 12 - electronic thermometer; 13 - water-sludge mixture; 14 - inert brush loading; 15 - distribution 
pipeline of a water regenerator; 16 - distribution pipeline of a medium-bubble regenerator; 17 hydraulic nozzles for air injection; 18 - suction branch pipe with holes for intake of water-sludge mixture from the bioreactor; 19, 20 - luxmeter; 21 - lamp for illumination of water-sludge mixture.

An inert synthetic brush loading (14) placed on a frame was placed in the model of the aerotank-bioreactor. The brush loading were attached to the frame vertically with a step of $100 \mathrm{~mm}$, so that there were $~ 50$ running meters of brush per $1 \mathrm{~m}^{3}$ of the volume of the model aerotank. The length of the synthetic brush with a diameter of $50 \mathrm{~mm}$ is $0.62 \mathrm{~m}$. The total length of the synthetic loading, consisting of seven brush, was $4.34 \mathrm{~m}$. The specific intensity of fine-bubble aeration of the water-sludge mixture was $5.41 \mathrm{~m}^{3} /\left(\mathrm{m}^{2} \cdot \mathrm{h}\right)$.

\subsection{Physical modeling of gas-hydrodynamic processes in an aerotank}

In real conditions of the aerotank operation, the free movement of bubbles is realized. At increase in the gas flow rate, dynamic effects begin to play a significant role, associated mainly with the acceleration of the liquid surrounding the bubble. In this mode, the detachment volume of the bubble and the detachment frequency increase with increasing gas flow rate. At high gas flow rates, the detachment frequency reaches an approximately constant level, and the bubble detachment volume increases approximately proportionally to the gas flow rate.

Of all the forces substantial for two-phase systems, only the surface tension forces tend to give the bubble a spherical shape, and the other forces tend to deform it [13-15].

The diameter of an air bubble is determined by the balance of pushing and retaining forces it (Figure 3), acting on the gas (air) bubble at the moment of its separation from the edge of the aerator pore [13].

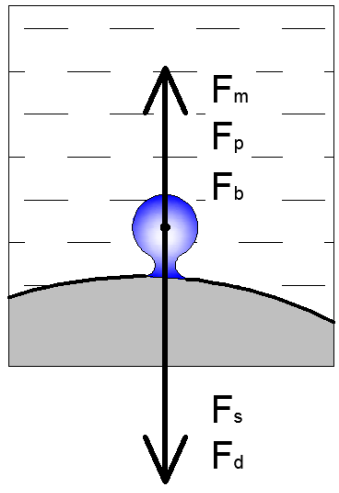

Fig. 3. Diagram of forces acting on a bubble of air coming out of a small-bubble aerator

The pushing forces that contribute to the detachment of the bubble include:

- Lifting (Archimedean) force:

$$
F_{b}=V_{b} \cdot \Delta \rho \cdot g
$$

where $V_{b}=\left(\pi \cdot d_{q}^{3}\right) / 6$ - volume of the bubble, $\mathrm{m}^{3} ; \Delta \rho$ - density difference of liquid and gas, $\mathrm{kg} / \mathrm{m}^{3} ; \mathrm{g}$ - acceleration of free fall, $\mathrm{m} / \mathrm{s}^{2}$.

- Force caused by uncompensated pressure difference:

$$
F_{p}=\pi \cdot d_{n}^{3} \cdot \sigma / D_{b}
$$

where $d_{n}$ - pore diameter of aerator, $\mathrm{m} ; \sigma-$ surface tension coefficient, $\mathrm{N} / \mathrm{m} ; D_{b}-$ bubble diameter (diameter of a sphere whose volume is equal to the volume of the bubble), $\mathrm{m}$. 
- Force resulting from the conversion of a dynamic pressure to a static pressure inside a gas bubble:

$$
F_{m}=\frac{\pi}{4} \cdot d_{n}^{2} \cdot \rho_{q} \cdot \omega_{q}^{2},
$$

where $\rho_{\mathrm{q}}-$ air density under actual conditions, $\mathrm{kg} / \mathrm{m}^{3} ; \omega_{\mathrm{q}}-$ air flow rate through the pore of the aerator, $\mathrm{m} / \mathrm{s}$.

The holding forces that prevent the detachment of the bubble include:

- The force of surface tension:

$$
F_{s}=\pi \cdot d_{n} \cdot \sigma .
$$

- The force of hydraulic resistance the ascent of the bubble:

$$
F_{d}=S_{b} \cdot \varepsilon_{d} \cdot \frac{\rho_{f} \omega_{r}^{2}}{2},
$$

where $S_{\mathrm{b}}$ - cross-sectional area of the bubble, $\mathrm{m}^{2} ; \rho_{\mathrm{f}}-$ density of water, $\mathrm{kg} / \mathrm{m}^{3} ; \varepsilon_{\mathrm{d}}-$ the coefficient of hydraulic resistance of a bubble in water, for bubbles with a diameter of 1 to $6 \mathrm{~mm}$, it can be taken equal to $0.445 ; \omega_{r}$ - growth rate of a single bubble.

The possibility of physical modeling of hydrodynamic processes in the aerotank is determined by air bubbles coming out of the aerator, the sizes of which are determined by the material of the filtering surface, as well as the bubble rise rate, which causes the airlift movement of the water flow. The equations describing one or another class of physical processes can always be presented in dimensionless form. The number of dimensionless parameters should be less than the number of dimensional parameters, and their value does not depend on the choice of the system of measures. This determines the advantage based on the analysis of experimental data in dimensionless complexes.

The speed of water movement $v_{\mathrm{f}}$ in the aerotank depends on the difference in the densities of the liquid and gas $\Delta \rho$, the density $\rho_{\mathrm{f}}$ and viscosity $\mu_{\mathrm{f}}$ of the liquid, the acceleration of gravity $\mathrm{g}$, the equivalent diameter $d_{\mathrm{q}}$ of the air gas bubbles, the speed of gas outflow from the surface of the aerator $v_{\mathrm{q}}$, the density of the gas $\rho_{\mathrm{q}}$ and the surface tension $\sigma$.

Thus, the functional dependence of the general form can be represented by the following equation:

$$
v_{f}=f\left(\Delta \rho, \rho_{f}, \mu_{f}, g, d_{q}, v_{q}, \rho_{q}, \sigma\right)
$$

or

$$
\Delta \rho=\varphi\left(v_{f}, \rho_{f}, \mu_{f}, g, d_{q}, v_{q}, \rho_{q}, \sigma\right) .
$$

To find a specific type of this functional dependence, i.e. finding the design equation, we apply the method of dimensional analysis. Let us represent function (1) as a power equation:

$$
\Delta \rho=x \cdot v_{f}^{y} \cdot \rho_{f}^{z} \cdot \mu_{f}^{u} \cdot g^{r} \cdot d_{q}^{t} \cdot v_{q}^{h} \cdot \rho_{q}^{k} \cdot \sigma^{w},
$$

where $x, y, z, u, r, t, h, k$ and $w$ - unknown numeric parameters.

Let us express the dimensions of all the quantities included in equation (7) in units of length, time and mass, and, taking into account that the dimensions of both parts of equation (7) are the same, and $\mathrm{x}$ is a dimensionless coefficient, we replace all quantities in it with their dimensions:

$$
[\Delta \rho]=\left[v_{f}\right]^{y}\left[\rho_{f}\right]^{z}\left[\mu_{f}\right]^{u}[g]^{r}\left[d_{q}\right]^{t}\left[v_{q}\right]^{h}\left[\rho_{q}\right]^{k}[\sigma]^{w},
$$

Substituting the obtained values of $y, z$ and $t$ into equation (7) and grouping the individual quantities by powers of $u, r, h, k$ and $w$, we get: 


$$
\frac{\Delta \rho}{\rho_{f}}=x \cdot\left(\frac{\mu_{f}}{v_{f} \cdot \rho_{f} \cdot d_{q}}\right)^{u} \cdot\left(\frac{g \cdot d_{q}}{v_{f}^{2}}\right)^{r} \cdot\left(\frac{v_{q}}{v_{f}}\right)^{h} \cdot\left(\frac{\rho_{q}}{\rho_{f}}\right)^{k} \cdot\left(\frac{\sigma}{v_{f}^{2} \cdot \rho_{f} \cdot d_{q}}\right)^{w},
$$

where $\left(v_{f} \cdot \rho_{f} \cdot d_{q}\right) / \mu_{f}=R e-$ Reynolds criterion, reflects the effect of friction force on fluid movement. Its value characterizes the ratio of inertial forces to friction forces in similar flows;

$v_{f}^{2} /\left(g \cdot d_{q}\right)=F r-$ Froude's criterion, which reflects the influence of gravity or its own weight on the movement of a liquid, is a measure of the ratio of inertia to gravity at similar points;

$\sigma /\left(v_{f}^{2} \cdot \rho_{f} \cdot d_{q}\right)=W e-$ Weber's criterion, determines the ratio of fluid inertia to surface tension. Its value is a measure of the entrainment of the liquid behind the body moving in it.

Thus, the sought-for function is presented as a ratio between six dimensionless complexes:

$$
\frac{\Delta \rho}{\rho_{f}}=x \cdot \operatorname{Re}^{-u} \cdot F r^{-r} \cdot W e^{w}\left(\frac{v_{q}}{v_{f}}\right)^{h} \cdot\left(\frac{\rho_{q}}{\rho_{f}}\right)^{k} .
$$

The consequence of the fulfillment of the conditions on the right side of this equation will be the equality of the values of the determined criterion $\Delta \rho / \rho_{\mathrm{f}}$ at like points of similar fluid flows in the model of the aero tank-bioreactor and in the real aerotank. By processing the experimental data obtained on the model, it is possible to find the numerical values of the coefficient $x$ and the exponents $-u,-r, w, h, k$ for the corresponding similarity.

Provided that the speed of liquid movement in the production aerated facility for biological wastewater treatment and in the model aerotank-bioreactor are identical, and other parameters are unchanged $\left(\rho_{\mathrm{f}}, \mu_{\mathrm{f}}, \rho_{\mathrm{q}}, v_{\mathrm{q}}\right.$ и $\sigma=$ const), the dimensionless criteria included in the right part of equation (10) are identical:

$$
R e=i d e m, F r=i d e m, W e=i d e m, \frac{v_{q}}{v_{f}}=i d e m, \frac{\rho_{q}}{\rho_{f}}=i d e m .
$$

Then functional dependence (10) in the first approximation describes similar hydrodynamic processes that take place in the physical model and the aerotank, provided that identical aerators are used. This makes it possible to transfer experimental data obtained on a model bioreactor to industrial aerated wastewater treatment facilities in the first approximation.

\subsection{Optical method for determining the concentration of floating sludge}

An optical method was used to determine the concentration of activated sludge in a freefloating or immobilized state. The method consisted in determining the intensity of light passing through a water-sludge layer moving in a flat model of aerotank-bioreactor [3, 4]. The design of the model bioreactor made it possible to measure the intensity of the light flux passing through the layer of the water-sludge mixture at a model width of $0.05 \mathrm{~m}$.

To determine the concentration of free floating activated sludge $\left(C_{\mathrm{F}}\right)$ in the central part of the aerotank-bioreactor, the method of calibration graph was used - the dependence of the concentration of free-floating $C_{\mathrm{F}}$ sludge on the intensity of light flux $\lambda$ (Figure 4).

The resulting dependence is described by equation (11) with the coefficient of determination $\mathrm{R}=0,9858$ :

$$
C_{F}=-0,0819 \cdot \ln (\lambda)+0,6385,
$$




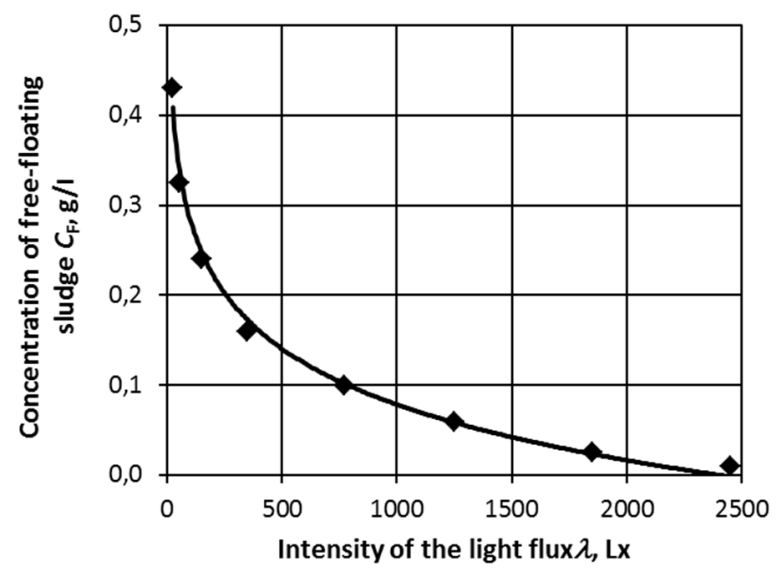

Fig. 4. Dependence of free-floating sludge in a model bioreactor on the intensity of light flux

To build a calibration graph, the intensity of the light flux passing through the layer of water-sludge mixture was measured with a luxmeter in the control square (Figure 5). Simultaneously the water-sludge mixture was taken using a siphon into a calibrated flask. From the difference in the masses of the flask with water and with a water-sludge mixture, the concentration of free-floating sludge was determined in a controlled square.

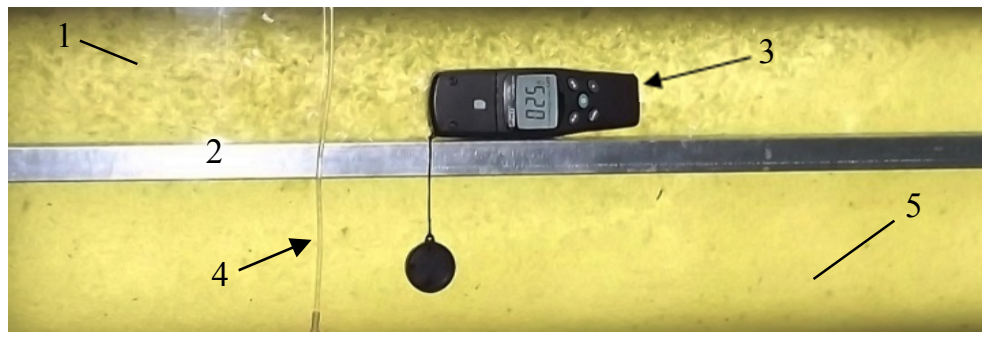

Fig. 5. Measurement of the light intensity passing through the water-sludge mixture in the control square of the model bioreactor: 1 - flakes of coagulated sludge; 2 - guide rail; 3 - luxmeter NT 307; 4 - siphon tube for sampling the water-sludge mixture; 5 - dispersed activated sludge

Sludge with a sludge index of $140 \mathrm{~cm}^{3} / \mathrm{g}$, used in the experiment, was taken from the secondary sedimentation tank of the right-bank sewage treatment facilities in Irkutsk. Using the weighing method, the total concentration of sludge in the model aerotank-bioreactor was set by adding activated sludge to the model bioreactor.

The resulting calibration graph and mathematical expression (11) were used for the express conversion of the illumination intensity values into the concentration of freefloating sludge using a simple calculation complex. All values of the intensity of the luminous flux for the calibration graph were measured in the area of the stagnant zone, since it is in the brush loading that the values of the velocities of the water-sludge mixture are approximately $0.075 \mathrm{~m} / \mathrm{s}$ or less.

\section{Discussion of the results}

Wastewater treatment in a bioreactor model with a brush loading and with fine-bubble aeration of a water-sludge mixture, without regeneration of immobilized sludge, made it possible to reduce $\mathrm{BOD}_{5}$ from $125 \mathrm{mg} / \mathrm{dm}^{3}$ to $40 \mathrm{mg} / \mathrm{dm}^{3}$ in three hours (Table 1). 
Table 1. Indicators of wastewater treatment using two sludge biocenoses in a bioreactor model

\begin{tabular}{|c|c|c|c|c|}
\hline \multirow{2}{*}{ Indicator } & \multicolumn{4}{|c|}{ Number of the sample that is taken every hour } \\
\hline & №1 & №2 & №3 & №4 \\
\hline \multicolumn{5}{|c|}{ without regenerating of immobilized sludge } \\
\hline Dissolved oxygen, $\mathrm{mg} / \mathrm{dm}^{3}$ & 2,22 & 2,34 & 2,61 & 2,78 \\
\hline $\mathrm{BOD}_{5}, \mathrm{mg} / \mathrm{dm}^{3}$ & 125 & 79 & 56 & 40 \\
\hline \multicolumn{5}{|c|}{ with the regeneration of immobilized sludge } \\
\hline Dissolved oxygen, $\mathrm{mg} / \mathrm{dm}^{3}$ & 2,38 & 2,49 & 2,78 & 2,91 \\
\hline BOD $5, \mathbf{m g} / \mathrm{dm}^{3}$ & 121 & 70 & 38 & 11 \\
\hline
\end{tabular}

The kinetic dependence of $\mathrm{BOD}_{5}$ for the experiment performed has a power-law character and is shown in Figure 6.

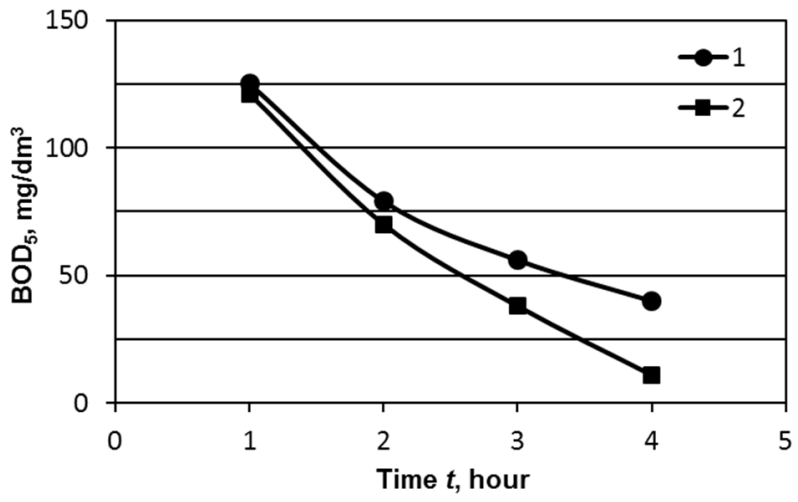

Fig. 6. Dynamics of $\mathrm{BOD}_{5}: 1$ - without regenerating of immobilized sludge; 2 - with the regeneration of immobilized sludge

The decrease in $\mathrm{BOD}_{5}$ during the first hour of the experiment is almost identical in both cases, and for the second and third hours there are visible differences. The decrease in $\mathrm{BOD}_{5}$, in the experiment without air regeneration, proceeds smoothly and reaches a value of $40 \mathrm{mg} / \mathrm{dm}^{3}$. Periodic regeneration of a brush loading with an intensity of $7.47 \mathrm{~m}^{3} /\left(\mathrm{m}^{2} \cdot \mathrm{h}\right)$, within two minutes, allows the $\mathrm{BOD}_{5}$ to be reduced to $11 \mathrm{mg} / \mathrm{dm}^{3}$ over the same period of time.

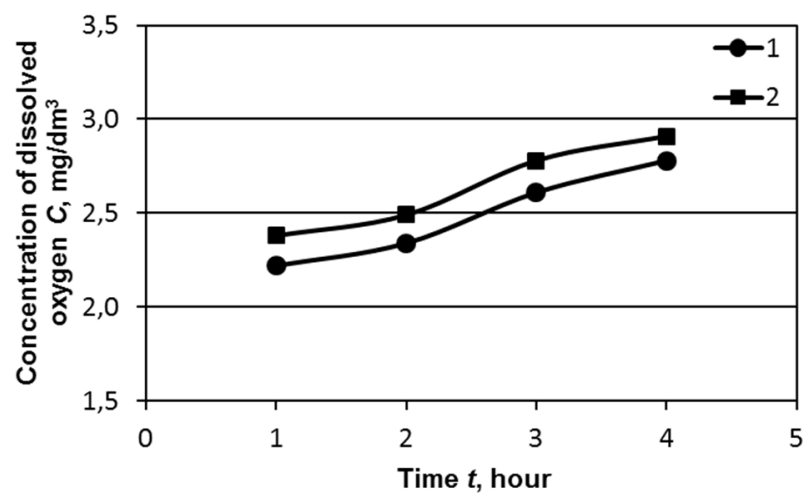

Fig. 7. Dynamics of dissolved oxygen concentration: 1 - without regenerating of immobilized sludge; 2 - with the regeneration of immobilized sludge 
The value of concentration of dissolved oxygen increased during the experiment from $2.22 \mathrm{mg} / \mathrm{dm}^{3}$ to $2.78 \mathrm{mg} / \mathrm{dm}^{3}$ without regeneration and from $2.38 \mathrm{mg} / \mathrm{dm}^{3}$ to $2.91 \mathrm{mg} / \mathrm{dm}^{3}$ with the regeneration of immobilized sludge (Figure 7). The change in the concentration of dissolved oxygen increases smoothly and reaches a maximum value of $2.91 \mathrm{mg} / \mathrm{dm}^{3}$ in laboratory experiments with the regeneration of immobilized sludge.

The rate of change in $\mathrm{BOD}_{5}$ (Figure 8) decreases from $46 \mathrm{mg} /\left(\mathrm{dm}^{3} \cdot \mathrm{h}\right)$ to $24 \mathrm{mg} /\left(\mathrm{dm}^{3} \cdot \mathrm{h}\right)$ in the stationary process of biological wastewater treatment according to the power law and is described by the expression

$$
v=7 t^{2}-40 t+84
$$

where $\mathrm{v}$ - rate of change in $\mathrm{BOD}_{5}, \mathrm{mg} /\left(\mathrm{dm}^{3} \cdot \mathrm{h}\right) ; \mathrm{t}$ - time of the experiment, hour.

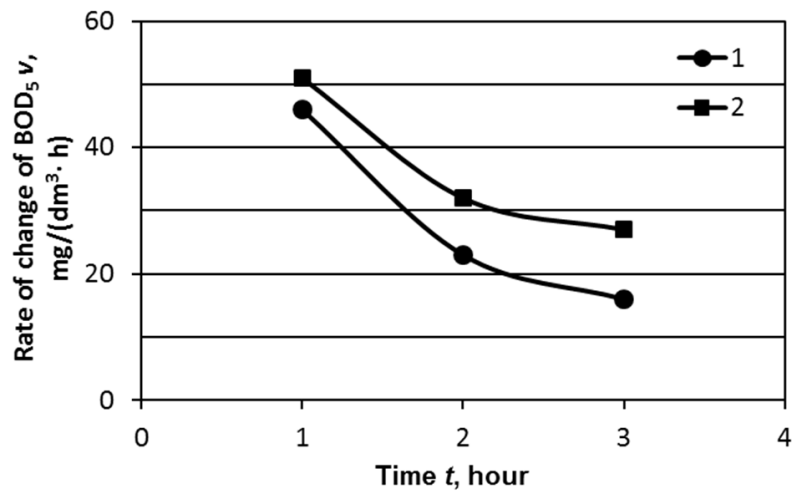

Fig. 8. Rate of change in BOD5: 1 - without regenerating of immobilized sludge; 2 - with the regeneration of immobilized sludge

The obtained mathematical expression makes it possible to calculate the rate of biological wastewater treatment at any time with a dose of activated sludge of $1.5 \div 2 \mathrm{~g} / \mathrm{dm}^{3}$ and a specific aeration intensity of the water-sludge mixture of $5.41 \mathrm{~m}^{3} /\left(\mathrm{m}^{2} \cdot \mathrm{h}\right)$.

The use of periodic regeneration of the immobilized sludge adsorbed on the loading with a regeneration intensify of $7.47 \mathrm{~m}^{3} /\left(\mathrm{m}^{2} \cdot \mathrm{h}\right)$, for two minutes, makes it possible to intensify the waste water purification process. Regeneration of the brush loading was carried before sampling through every hour. The presence of two biocenoses, free floating and immobilized regenerated, increased the rate of $\mathrm{BOD}_{5}$ change by $\sim 7 \%$. This dependence also has a power-law character and is described by expression (13).

$$
v=8 t^{2}-47 t+85
$$

Conducting an experiment on the biological treatment of domestic wastewater for 4 hours, with periodic regeneration of silt, changed the $\mathrm{BOD}_{5}$ from $121 \mathrm{mg} / \mathrm{dm}^{3}$ to 11 $\mathrm{mg} / \mathrm{dm}^{3}$. The value of concentration of dissolved oxygen in the water-sludge mixture increased from $2.38 \mathrm{mg} / \mathrm{dm}^{3}$ to $2.91 \mathrm{mg} / \mathrm{dm}^{3}$. Thus, the use of renewed regenerated immobilized sludge made it possible to achieve a deeper purification of waste water.

\section{Conclusion}

The possibility of using physical modeling to study the gas-hydrodynamic environment in an aerotank-bioreactor is shown. A physical model of a bioreactor has been made, which is a cross-sectional vertical section of an industrial aerotank-bioreactor.

Shown is the intensification of waste water treatment using regenerative immobilized activated sludge. The efficiency of water purification with the regeneration of immobilized sludge is $\sim 3$ times higher than in stationary water purification technology. 
The kinetics of BOD5 and dissolved oxygen has been studied during biological wastewater treatment in a bioreactor, with sludge immobilized on a brush loading and free floating sludge. The speed of water purification decreased by $\sim 2$ times in three hours of the experiment. The concentration of dissolved oxygen, during this time, decreased by $\sim 20 \%$ with the use of regeneration and without it. Mathematical expressions have been obtained that allow calculating the rate of change in $\mathrm{BOD}_{5}$ over time.

It is shown that the periodic regeneration (renewal) of the immobilized sludge makes it possible to increase the rate and depth of wastewater treatment.

\section{References}

1. N.S. Zhmur, Technological and biochemical processes of waste water treatment on constructions with aerotanks (AKVAROS, Moscow, 2003)

2. N.I. Kulikov, A.Y. Rymanov, N.P. Omelchenko, V.N. Chernyshov, Theory of water purification (Noulidzh, Donetsk, 2009)

3. V.N. Kul'kov, E.Yu. Solopanov, V.M. Sosna, Proceedings of the Universities. Investment. Construction. Real estate, 2, 146 (2016)

4. V.N. Kul'kov, E.Yu. Solopanov, Proceedings of the Universities. Investment. Construction. Real estate, 3, 77 (2016)

5. V.N. Shvetsov, K.M. Morozova, I.I. Smirnova, M.Yu. Semenov, M.L. Lezhnev, G.G. Ryzhakov, A.A. Krasnov, VST, 2, 33 (2007)

6. N. Dizge, B. Tansel, B. Sizirici. Chem Eng Process, 8, 766 (2011)

7. Yu.A. Ermolin, M.I. Alekseev, Water Ecol., 2, 18 (2017)

8. M.C. Martí-Calatayud, S. Schneider, S. Yüce, M. Wessling, Water research, 147, 393 (2018)

9. Khaled Zaher Abdalla, Khaled Khafagy, IJSER, 5, issue 2, 619 (2014)

10. R.A. Hamza, Z. Sheng, O.T. Iorhemen, M.S. Zaghloul, Joo Hwa Tay, Water research., 147, 287 (2018)

11. V.N. Shvetsov, K.M. Morozova, I.I. Smirnova, M.Yu. Semenov, M.L. Lezhnev, G.G. Ryzhakov, T.M. Gubaidullin, VST., 10-2, 25 (2010)

12. E.Yu. Solopanov, V.N. Kulkov, A.E. Shirokov, Proceedings of the Universities. Investment. Construction. Real Estate, 4, 138 (2016)

13. Yu.M. Meshengisser, Theoretical substantiation and development of new polymer aerators for biological wastewater treatment (FSUE "NII VODGEO", Moscow, 2005)

14. I.O. Protodyakonov, Yu.G. Chesnokov, Hydrome-chanical Foundations of Chemical Technology Processes (Chemistry, Leningrad, 1987)

15. A.V. Klimenko, V.M. Zorin, Theoretical Founda-tions of Heat Engineering. Heat engineering experiment. Directory, vol. 2 (MPEI Publ., Moscow, 2007) 